\title{
Níveis séricos de cálcio e fósforo de bovinos mestiços do agreste de Pernambuco
}

\section{Half-breeds bovines serics calcium and phosphorus levels from the meridional rural of Pernambuco State}

\author{
Eneida Willcox Rêgo, ${ }^{1 *}$ Emiko Shinozaki Mendes, ${ }^{*}$ Lúcio Esmeraldo Honório de Melo, ${ }^{*}$ Adriano Fernandes Ferreira, ${ }^{* *}$ \\ Roniery Carlos Gonçalves Galindo***
}

\begin{abstract}
Resumo
Determinaram-se teores de cálcio e fósforo séricos, em amostras de sangue procedentes de bovinos mestiços (holandozebu), machos e fêmeas, entre quatro e 168 meses de idade, do município de Garanhuns (mesorregião Agreste de Pernambuco). As médias dos 251 animais testados foram 8,50 $\pm 0,23 \mathrm{mg} \%$ e 6,89 $\pm 0,32 \mathrm{mg} \%$, para cálcio e fósforo respectivamente, concluindo-se que tais resultados são semelhantes aos da literatura consultada.
\end{abstract}

Palavras-chave: ruminantes, calcemia, fosfatemia.

\begin{abstract}
The present work shows the half-breeds, males and females bovines sericals substances of calcium and phosphorus, with age between four and 168 months, from Garanhuns (Meridional Rural of Pernambuco). The relatives averages to the sanguineous values of calcium and phosphorus of the 251 animals examined were $8,50 \pm 0,23 \mathrm{mg} \%$ and 6,89 $\pm 0,32 \mathrm{mg} \%$ respectively, concluding that this results were similar to the consulted literature.
\end{abstract}

Keywords: ruminants, calcemy, phosphatemy.

\section{Introdução}

Cada vez é mais necessária a suplementação mineral na alimentação animal, cuja carência desses nutrientes tem ocasionado, em rebanho bovino, a presença de animais magros, com desenvolvimento retardado e deficiente produção de carne e leite.

Para o efetivo suprimento de minerais na dieta animal é necessário o conhecimento dos níveis normais desses elementos no soro sangüíneo e em outros órgãos. Estes parâmetros têm sido estudados por vários autores.

Para Braz (1972), o interesse em estabelecer os valores sangüíneos do cálcio e fósforo reside, ainda, na relação entre as variações quantitativas orgânicas e as osteopatias quimiodistróficas, onde se inclui o raquitismo, a osteomalácia, a osteofibrose, entre outras alterações.

Deste modo, níveis séricos de cálcio e fósforo foram determinados em amostras sangüíneas de bovinos criados na mesorregião Agreste de Pernambuco, com a finalidade de contribuir com estudos dessa natureza, concernentes ao Nordeste brasileiro. Além disso, objetivou-se subsidiar a clínica médica veterinária com valores referenciais da calcemia e fosfatemia em bovinos, uma vez que os valores de que se dispõe são baseados em dados de outras regiões ou países, onde predominam as raças puras, de manejo e condições edafo-climáticas diferentes.

\section{Material e métodos}

Níveis séricos de cálcio e fósforo foram determinados em amostras de sangue de 251 bovinos mestiços de Gir x Holandês; machos e fêmeas, com idades variando de quatro a 168 meses, provenientes de 30 criatórios, localizados em Garanhuns, município da mesorregião Agreste de Pernambuco.

As análises foram efetuadas no Laboratório de Patologia Clínica Veterinária do Departamento de Medicina Veterinária da Universidade Federal Rural de Pernambuco (UFRPE).

$O$ sangue foi colhido mediante venopunção jugular em frascos sem anticoagulante. Imediatamente após a formação do coágulo e sua respectiva retração, o soro foi removido por decantação, centrifugado e mantido sob refrigeração ou congelamento até o processamento, por um período máximo de cinco dias, de acordo com a recomendação de Archer (1965) e Kaneko (1989).

\footnotetext{
*Professor Adjunto da Universidade Federal de Pernambuco/DMV - Rua Dom Manuel de Medeiros, S/N, dois Irmãos - CEP 52171-900 - Recife, PE

** Professor Substituto da Universidade Federal do Rio Grande do Norte/Esc. de Vet. - Mossoró

*** Professor Associado do Centro de Ensino Superior de Maceió, AL

${ }^{1}$ Autor para correspondência: ewillcox@bol.com.br
} 
Amostras hemolisadas foram descartadas, uma vez que poderiam apresentar taxas falsamente altas do fósforo, conforme recomendado por Duncan e Prasse (1982). A obtenção destes resultados pode ser devido aos ésteres de fosfato contidos nos eritrócitos apresentarem grande susceptibilidade à hidrólise, quando liberados pelas hemácias rompidas (Kelly, 1986).

As análises do fósforo inorgânico e cálcio total, isto é, cálcio ionizado mais cálcio ligado às proteínas (Duncan e Prasse, 1982), foram realizadas pelo método colorimétrico, utilizando-se kits comerciais ${ }^{1}$ para dosagens bioquímicas, com leituras em espectrofotômetro, ${ }^{2}$ segundo técnicas descritas por Coles (1984) e Kaneko (1989).

\section{Resultados e discussão}

Os teores séricos mínimos e máximos de cálcio e fósforo nos 251 animais estudados, bem como as estatísticas descritivas, estão na Tabela 1.

Tabela 1: Estatísticas descritivas e limites extremos da calcemia e fosfatemia de bovinos do Agreste de Pernambuco.

\begin{tabular}{cccccc}
\hline $\begin{array}{c}\text { Elemento } \\
(\mathrm{mg} \%)\end{array}$ & $\mathrm{X}$ & $\mathrm{S}$ & $\begin{array}{c}\text { C.V. } \\
\%\end{array}$ & Máximo & Mínimo \\
\hline Cálcio & 8,50 & $\pm 3,64$ & 21,92 & 13,60 & 3,10 \\
Fósforo & 6,89 & $\pm 5,07$ & 37,80 & 16,90 & 1,70 \\
\hline
\end{tabular}

$\mathrm{X}=$ média; $\mathrm{S}$ = desvio padrão; C. V. = Coeficiente de Variação.

Observa-se na Tabela 1 que os coeficientes de variação foram elevados, em virtude da grande amplitude entre esses níveis, cujos valores máximos e mínimos divergiram daqueles apresentados na literatura consultada (Tabela 2) concordando, entretanto, com os valores médios obtidos.

Tabela 2: Valores séricos de cálcio e fósforo em bovinos.

\begin{tabular}{lcc}
\hline REFERÉNCIAS & Cálcio $(\mathrm{mg} \%)$ & Fósforo $(\mathrm{mg} \%)$ \\
\hline Mancuso (1972) & $9,58 \pm 1,07$ & 4,07 a 9,11 \\
Mancuso (1974) & $9,25 \pm 1,49$ & 3,59 a 8,79 \\
Ferreira Neto et al. (1978) & 8,50 a 11,6 & $5,56 \pm 1,56$ \\
Gautier (1978) & 10,0 & 5,60 a 9,50 \\
Coles (1984) & 11,8 & 4,0 a 7,12 \\
Matos e Matos (1988) & 8,0 a 9,25 & 4,17 \\
Silveira (1988) & 9,40 a 12,20 & 4,0 a 7,0 \\
Birgel et al. (1991) & 9,12 a 11,12 & 6,41 a 9,41 \\
Souza (1997) & 8,54 a 10,21 & 5,90 a 9,47 \\
\hline
\end{tabular}

Na Tabela 3 é possível a observação da distribuição da freqüência da calcemia e fosfatemia. Verifica-se que em relação ao cálcio, a maioria dos animais $(85,65 \%)$ apresentou teores de 6,0 a $11,0 \mathrm{mg} \%$, sendo a maior freqüência encontrada na

\footnotetext{
${ }^{1}$ DOLES - Reagentes e equipamentos para laboratórios Ltda.

2 Colemann Júnior III
}

faixa de 8,0 a $9,0 \mathrm{mg} \%$ (23,90\%). Quanto ao fósforo, a maior freqüência ocorreu na faixa de 6,0 a $7,0 \mathrm{mg} \%(19,12 \%)$, enquanto a maioria dos bovinos mostrou teores de 4,0 a $8,0 \mathrm{mg} \%$ $(62,15 \%)$.

Comparando-se os resultados apresentados na Tabela 3 aos obtidos por Ribeiro et al. (1980), ao estudarem 1.711 bovinos mestiços, verifica-se que: a) no que concerne ao cálcio sérico, $20,8 \%$ dos animais apresentaram teores acima de $9,34 \mathrm{mg} \%$; $52 \%$ mostraram índices abaixo desse valor e 17,2\% tiveram níveis abaixo de 8,0mg\%; b) em relação ao fósforo, 9,5\% estavam com valores abaixo de $4,0 \mathrm{mg} \%$, enquanto $76,90 \%$ estavam dentro dos limites normais. As diferenças entre esses resultados são, provavelmente, devido ao clima, sistema de criação, ou seja, tipo de manejo de um modo geral.

Tabela 3: Distribuição da freqüência dos níveis séricos de cálcio e fósforo em bovinos do Agreste de Pernambuco.

\begin{tabular}{ccccccc}
\hline \multicolumn{2}{c}{ CLASSE } & \multicolumn{3}{c}{ CÁLCIO } & \multicolumn{2}{c}{ FÓSFORO } \\
\hline \multicolumn{2}{c}{ Ca/P $(\mathrm{mg} \%)$} & Freqüência & Percentagem & Freqüência & Percentagem \\
\hline 1,0 & $\neg$ & 2,0 & - & - & 3 & 1,20 \\
2,0 & \urcorner & 3,0 & - & - & 4 & 1,59 \\
3,0 & $\neg$ & 4,0 & 6 & 2,39 & 18 & 7,17 \\
4,0 & $\neg$ & & 3 & 1,20 & 31 & 12,35 \\
5,0 & $\neg$ & 6,0 & 10 & 3,98 & 45 & 17,93 \\
6,0 & $\neg$ & 7,0 & 35 & 13,94 & 48 & 19,12 \\
7,0 & $\neg$ & 8,0 & 32 & 12,75 & 32 & 12,75 \\
8,0 & $\neg$ & 9,0 & 60 & 23,90 & 18 & 7,17 \\
9,0 & $\neg$ & 10,0 & 50 & 19,92 & 20 & 7,97 \\
10,0 & $\neg$ & 11,0 & 38 & 15,14 & 12 & 4,78 \\
11,0 & $\neg$ & 12,0 & 5 & 1,99 & 7 & 2,79 \\
12,0 & $\neg$ & 13,0 & 11 & 4,39 & 7 & 2,78 \\
13,0 & $\neg$ & 14,0 & 1 & 0,40 & 2 & 0,80 \\
14,0 & $\neg$ & 15,0 & - & & 1 & 0,40 \\
15,0 & $\neg$ & 16,0 & & & 2 & 0,80 \\
16,0 & $\neg$ & 17,0 & & & 1 & 0,40 \\
\hline TOTAL & & & 251 & 100,00 & 251 & 100,00 \\
\hline
\end{tabular}

Muitas variáveis, que não foram isoladas, podem ter interferido nos resultados, como a raça (Dayrell et al., 1972; Souza, 1997), estação do ano (Nascimento et al., 1986), ciclo reprodutivo (Pjescák et al., 1981; Kozlowska et al., 1981) e idade (Souza, 1997), apesar de Kelly (1986) haver citado que, embora muitos fatores façam variar os níveis séricos, a idade parece não ter influência significativa sobre os níveis de cálcio, para esse autor.

Além de tais fatores interferirem nas variações do cálcio e fósforo séricos, Duncan e Prasse (1982) advogaram que distúrbios do metabolismo envolvendo esses elementos podem ocorrer por alterações do hormônio paratireoidiano (HPT), ou por mecanismos não esclarecidos.

$\mathrm{Na}$ distribuição de freqüência dos níveis séricos de cálcio e fósforo (Tabela 3) percebe-se grande variação, porém não extrapolando a maioria dos limites determinados pelos diversos autores compulsados (Tabela 2), levando-se a crer que: 
a) não se determinou o estado de higidez dos animais através de exames profundos e detalhados, das diversas funções biológicas, admitindo-se que pode ter havido a inclusão de indivíduos não sadios (Mancuso, 1972);

b) os ruminantes podem tolerar uma larga variação das taxas de cálcio e fósforo séricos (Valent et al., 1980), razão pela qual sejam aceitos os valores encontrados nesta pesquisa;

c) os níveis séricos dos elementos podem variar bastante, não apenas pela dieta, idade, como também em vista da presença de helmintos gastrintestinais, muito comum em nosso meio, que possivelmente prejudicam a absorção de substâncias alimentares, entre elas, o fósforo (Nascimento et al., 1986). Algumas parasitoses podem passar

\section{Referências}

ARCHER, R. K. Hematological techniques for use on animals. Oxford: Blackwell Scientific, 1965. $135 \mathrm{p}$.

BRAZ, M. B. Semiologia médica animal. Lisboa: Fundação Calouste Gulbenkian, 1972. Cap. 6, p.171-284: Semiologia do sangue e dos órgãos hematopoéticos.

BIRGEL, E. H.;BIRGELJÚNIOR, E. H.; MIRANDOLA, R. M. S.; PEREZ, M. J. V.; GREGORY, L. Padrões bioquímicos de soro sangüíneo de bovinos da raça Jersey, criados no Estado de São Paulo: parâmetros para avaliação da função hepática. In: CONFERÊNCIA ANUAL DA SOCIEDADE PAULISTA DE MEDICINA VETERINÁRIA, 46. São Paulo, 1991. Anais. p. 44.

COLES, E. H. Patologia clínica veterinária. 3. ed. São Paulo: Manole, 1984. Cap. 12, p. 300-313: Equilíbrio mineral e função da paratireóide. DAYRELL, M. S.; LOPES, H. S.; AROEIRA, J. A. D. C. et al. Teores de cálcio, magnésio, fósforo inorgânico e atividade da fosfatase no soro sangüíneo de bovinos criados no cerrado. Arquivos da Escola de Veterinária da Universidade Federal de Minas Gerais, Belo Horizonte, v. 24, n. 3, p. 265-274, 1972.

DUNCAN, J. R.; PRASSE, K. W. Patologia clínica veterinária. Rio de Janeiro: Guanabara Koogan, 1982. Cap. 9, p. 115-128: Sistema endócrino.

FERREIRA NETO, J. M.; VIANA, E. S. ; MAGALHÃES, L. M. Patologia clínica veterinária. 2. ed. Belo Horizonte: Rabelo e Brasil, 1978. Cap. 4, p. 131-163: Bioquímica do sangue.

GAUTIER, A. Os exames de laboratório na prática veterinária. São Paulo: Organização Andrei, 1978. 112 p.

KANEKO, J. J. Clinical biochemistry of domestic animals. 4. ed. New York: Academic Press, 1989. 832 p.

KELLY, W. R. Diagnóstico clínico veterinário. 3. ed. Rio de Janeiro: Interamericana, 1986. Cap. 13, p. 259-294: Sangue e órgãos formadores de sangue.

KOZLOWSKA, K.; ROGOWSKA-BIELICKA, W. ; SENKA, A. Calcium inorganic phosphorus and magnesium in serum of pregnat cows. Polskie Archiwum weterynaryjne, Polony, v. 23, n. 1, p. 63-70, 1981. MANCUSO, P. C. Níveis de cálcio, fósforo e magnésio em soros de bovinos do Rio Grande do Sul I. Guaíba, Livramento, Rio Pardo, Santo Antônio da Patrulha, São Francisco de Paula e São Gabriel. Boletim do Instituto de Pesquisas Desidério Finamor, Porto Alegre, v. 1, p. 11-21, 1972. despercebidas ao exame clínico, dependendo do grau de infestação;

d) é possível ter havido a inclusão nesta pesquisa de fêmeas em lactação. Neste caso, a calcemia e a fosfatemia podem sofrer variações (diminuição dos níveis) em razão do seqüestro desses elementos para a glândula mamária, conforme relatam Raviart et al. (1987).

\section{Conclusões}

Os níveis séricos de cálcio e fósforo determinados em bovinos mestiços da mesorregião Agreste de Pernambuco assemelharam-se aos encontrados pelos autores nacionais, em animais de diversos estados e apresentaram grande variação, provavelmente em virtude da interferência de fatores não isolados.

MANCUSO, P. C. Níveis de cálcio, fósforo e magnésio em soros de bovinos do Rio Grandedo Sul III. Cachoeira do Sul, Canoas, Encruzilhada do Sul, Lagoa Vermelha, São Jerônimo e Vacaria. Boletim do Instituto de Pesquisas Veterinárias Desidério Finamor, Porto Alegre, v. 2, p. 41-50, 1974.

MATOS, M. S.; MATOS, P. F. Laboratório clínico médico-veterinário. 2. ed. Rio de Janeiro: Atheneu, 1988. Cap. 8, p. 203-238: Bioquímica clínica.

NASCIMENTO, S. J.; NASCIMENTO, A. M. L. C.; GOMES, A.V. Dosagem de cálcio e fósforo em bovinos com helmintíase gastrointestinal naturalmente adquirida. Caderno Ômega da Universidade Federal Rural de Pernambuco. Série Veterinária, Recife, v. 2, p. 11-129, 1986.

PJESCÁK, M.; VALENT, M.; KOVÁCIK, J. Efect of the stage of the reprodutive cycle on the level of phosphorus compounds in the blood serum of high and low produzing dairy cows. Acta Zootechnica, Czeschoslovakia, v. 37, p. 21-35, 1981.

RAVIART, I.; BÈZILLE, P.; BRAUN, J. P. et al. Profils biochimics plasmatiques des chevreaux nouveaux-nés et dês mères. Recueil de Médicine Vétérinaire, v. 163, n. 5, p. 547-553, 1987.

RIBEIRO, A. das. G. P.; PINHEIRO, J. G.; NASCIMENTO, M. D. do. Valores bioquímicos de bovinos. I. Níveis séricos de cálcio e fósforo em vacas mestiças. Niterói: Empresa de Pesquisa Agropecuária do Estado do Rio de Janeiro., 1980. p. 1-3. (Comunicado Técnico, 56).

SILVEIRA, J. M. da. Interpretação de exames laboratoriais em veterinária. Rio de Janeiro: Guanabara Koogan, 1988. p. 202-210: Valores normais. Apêndice.

SOUZA, P. M. Perfil bioquímico sérico de bovinos das raças Gir, Holandesa e Girolanda, criados no Estado de São Paulo-influência de fatores de variabilidade etários e sexuais. São Paulo, 1997. 256 p. Tese (Doutorado)—Faculdade de Medicina Veterinária e Zootecnia, Universidade de São Paulo.

VALENT, M.; PJESCÁK, M.; KOLÁROVÁ, E. Study of calcium, inorganic phosphorus and magnesium ratios in the blood serum of milk cows in dependence on their utility and the sesson. Acta Zootechnica, Czeschoslovakia, v. 36, p. 28-35, 1980.

VIEIRA, S. Introdução à bioestatística. 5. ed. Rio de Janeiro: Campus, 1988, cap. 4, p. 65-75: medidas de dispersão ou de variabilidade para uma amostra. 